\title{
CARACTERÍSTICAS SOCIOCULTURAIS DE ESTUDANTES UNIVERSITÁRIOS NO INTERIOR DO AMAZONAS E SUAS RELAÇÕES COM A EDUCAÇÃO EM CIÊNCIAS
}

Welton Yudi Oda ${ }^{1}$

\begin{abstract}
RESUMO: O presente estudo envolveu 47 estudantes matriculados em disciplinas da Educação em Ciências pertencentes a dois municípios do interior do Amazonas, envolvendo um curso de licenciatura regular e dois cursos de Pedagogia ligados ao PARFOR. O contexto onde estão inseridos estes estudantes é o de baixos a médios índices de desenvolvimento humano, famílias de baixa renda e altos índices de analfabetismo. Os participantes da pesquisa possuem um perfil próximo do "novo" estudante universitário brasileiro, de família externa à cultura acadêmica, com pouca prática de leitura e escrita e filhos de trabalhadores. $O$ acesso que possuem a bens culturais restringe-se aos produtos da "indústria cultural", mas diferenças significativas foram observadas entre estudantes do curso regular quando comparados aos do PARFOR, já que os primeiros, sendo exclusivamente estudantes, possuem tempo livre para efetuar leituras e outras atividades acadêmicas, diferentemente dos segundos, que não possuem tal disponibilidade. Tal diferença não produziu desempenhos distintos entre os cursos, tendo ambos, apresentado deficiências na produção escrita, tanto estruturais quanto ligadas ao conteúdo científico. Sugere-se, neste contexto, a produção de atividades que levem em conta esta realidade e que contribuam para alterar este quadro, possibilitando o desenvolvimento paulatino da autonomia intelectual entre os estudantes, capacitando-os a realizar leituras mais frequentes e críticas.
\end{abstract}

Palavras-chave: Educação em Ciências; Amazonas; Leitura; Cultura.

ABSTRACT: The present study evolved 47 students of scientific education disciplines in two cities of the Amazonas state. These individuals are students of a regular Biology Teaching course and other two Pedagogy courses related to PARFOR. The context they live these students is to low to medium levels of human development, low-income families and high levels of illiteracy. Research participants have a profile close of the "new" brazilian university student, from a family external of a academic culture, without reading and writing practice, son of workers. The access to cultural elements are restrict to a products of a cultural industry, but significant differences were observed between students of the regular course when compared to the PARFOR, since the first ones, being exclusively students, possess free time to read and made other academic activities, different from the second ones, that don't possess this availability. These difference don't produce distinct performance between these courses, having both presented disabilities on the write production exercises, both

\footnotetext{
1 Docente do Instituto de Ciências Biológicas da Universidade Federal do Amazonas (UFAM). Doutor em Educação Científica e Tecnológica pela Universidade Federal de Santa Catarina (UFSC).
} 
structural and related to the scientific contents. It's suggested in this context the production of activities that take into account this reality and that contributes to change it, enabling the gradual developing of intelectual autonomy between the students, turn them capable to realize more frequent and critical reading activities.

Keywords: Science Education; Amazon; Reading; Culture.

\section{CARACTERIZANDO O “NOVO” ESTUDANTE UNIVERSITÁRIO BRASILEIRO}

As condições de acesso e permanência de estudantes brasileiros nos cursos universitários são bastante desiguais, privilegiando aqueles egressos das classes médias da população, excluindo, desse modo, em grande medida, estudantes de classes menos privilegiadas em renda e recursos escolares (MAURITTI, 2002; PORTES, 2006).

Muitos são os fatores que contribuem para essa desigualdade de oportunidades. Mauritti (2002), em estudo envolvendo padrões de vida de estudantes universitários portugueses, afirma que as chances que um estudante de origem burguesa tem de ingressar na universidade são 16 vezes superiores às de seus colegas que provem do operariado e, sendo filhos de pais universitários, de nove a vinte vezes mais chances de ingresso quando comparados a filhos de pais não-universitários. Essa desigualdade social é corroborada pelo estudo de Zago (2006), no Brasil, que diz, entre outras coisas, que, no contexto da Universidade Federal de Santa Catarina, há grande disparidade no perfil dos candidatos aprovados no vestibular e que, dentre os estudantes brasileiros oriundos de famílias de baixa renda, entre 18 e 24 anos, somente $9,0 \%$ frequenta o ensino superior. A referida autora, no estudo supracitado, afirma ainda que $25,0 \%$ dos potenciais estudantes universitários possuem renda insuficiente até mesmo para se manter numa instituição pública, mesmo que esta seja gratuita.

Estas diferenças socioculturais, disparidades nas condições sociais e materiais, além disso, produzem diferenças no domínio do conhecimento entre aqueles que, oriundos das camadas populares, frequentaram a escola pública em relação àqueles que, oriundos de classes mais privilegiadas, frequentaram escolas particulares e cursinhos preparatórios (ZAGO, 2006). 
Além disso, estas desigualdades situam-se igualmente em outras questões relativas ao modo como estes estudantes interagem com estes saberes. Segundo Britto et al. (2008), diferente do acadêmico tradicional, o estudante de origem popular pertence à primeira geração de longa escolaridade na família, sendo oriundo de uma camada social que privilegia formar-se para o mercado de trabalho, não dispondo de condições apropriadas para estudar, tendo formação primária e média insuficientes. Mais do que isso, seria razoável supor que, sendo pioneiros no ensino superior em suas famílias, com frequência, não puderam, no âmbito doméstico, cultivar, na idade escolar, o hábito da leitura e da escrita como prática social. Corroborando com a hipótese, os autores supracitados afirmam ser frequentemente documentadas, no aluno universitário de origem popular, ao qual os autores chamam de "o novo aluno" do ensino superior, características como a má escrita e a dificuldade de leitura. Por outro lado, estes autores consideram equivocado julgar o "novo aluno" tendo como base o estudante universitário clássico como referência.

Vale ressaltar que este "novo aluno" universitário, oriundo das camadas populares, descrito por Britto et al. (2008) no caso brasileiro, e por Mauritti (2002), em Portugal, não é um personagem frequente nos cursos ditos "mais prestigiosos" (como Medicina, Direito e Ciências da Computação), como observa Portes (2006). Ainda que tais cursos não constituam o escopo desta pesquisa, a referência a eles tenciona mostrar que esta renovação do perfil do aluno universitário não ocorre de modo homogêneo no interior destas instituições.

Fica evidenciado, nesta reflexão, que o domínio de hábitos (ler e escrever, por exemplo) e bens culturais valorizados no meio acadêmico (sobretudo os livros) constitui elemento de grande relevância no acesso, permanência e desempenho de estudantes nos cursos universitários, marcados ainda pelo formato "clássico". Dentre as competências oriundas do domínio desta cultura, podemos referir, por exemplo, aqueles indicados por Moraes et al. (2011) e que dizem respeito ao perfil do profissional que, no mundo contemporâneo, seria adequado para produzir desenvolvimento científico e tecnológico, como raciocínio lógico e abstrato, resolução de 
problemas, criatividade, capacidade de compreensão, julgamento crítico e conhecimento geral (características cognitivas); cooperação, iniciativa, (...) responsabilidade, participação, disciplina, ética, etc.

Algumas das questões que emergiram, ao investigar certos aspectos socioculturais em que estão inseridos estudantes universitários de uma instituição pública de ensino de duas cidades do interior do Amazonas, foram as seguintes:

a) Qual a relação destes estudantes com os hábitos e bens culturais mais valorizados no meio acadêmico, como o hábito da leitura e o contato com certos produtos artístico-culturais (filmes, músicas, obras literárias, etc.), a produção escrita, artística, técnica, entre outros?

b) De que modo estes elementos influenciam a aprendizagem das Ciências?

\section{CARACTERIZANDO O CONTEXTO SOCIOCULTURAL DOS PARTICIPANTES DA PESQUISA}

Buscando responder a estas questões aplicamos um questionário aos estudantes que teve como objetivos: a) obter informações sobre o perfil socioeconômico e cultural dos estudantes, visando planejar as disciplinas a partir de elementos de seu universo temático, de seus limites e possibilidades e; b) apresentar, de modo sumário, a eles, esta caracterização, tanto para que conheçam, sistematicamente, estas informações sobre seu próprio universo, como para que, como futuros professores, compreendam o papel e a importância de uma investigação desta natureza para a elaboração do planejamento de ensino.

O referido questionário foi composto por questões abertas e fechadas envolvendo, sobretudo os seguintes elementos: a) dados pessoais, como idade, gênero, estado civil, prole, formação básica, atividades extraacadêmicas, etc.; b) concepções de docência e de "bom professor"; c) dados socioculturais, como renda familiar mensal, religiosidade, participação em atividades sociais, leituras realizadas e prediletas, obras cinematográficas e músicas preferidas. 
A região escolhida para o desenvolvimento do estudo compreende dois municípios do interior do estado do Amazonas - Itacoatiara e Urucurituba - nos quais o autor desta pesquisa lecionou disciplinas no campo da Educação em Ciências. Estes dois municípios distam entre si cerca de 49 km, localizando-se, ambos, às margens do Rio Amazonas. Destas, Itacoatiara é a mais populosa, tendo cerca de 94 mil habitantes (BRASIL, 2013), sendo mais próxima de Manaus, localizando-se $176 \mathrm{~km}$ à leste desta. Já o município de Urucurituba possui cerca de 20 mil habitantes (BRASIL, 2013) e dista $192 \mathrm{~km}$ da capital, localizando-se à nordeste desta. A primeira possui acesso rodoviário a Manaus (AM - 010), enquanto a segunda liga-se por meio fluvial, tanto à Itacoatiara quanto à capital.

O Índice de Desenvolvimento Humano Municipal (IDHM) das cidades nas quais foi realizada a presente pesquisa é inferior à média nacional, estimada em 0,727 no ano de 2010, sendo este índice equivalente a 0,644 para o município de Itacoatiara e 0,588 no caso de Urucurituba (ONU, 2013). Segundo esta escala, o valor atribuído ao primeiro é considerado médio, enquanto aquele referente ao segundo é baixo. Os índices são variáveis conforme a região da cidade, sendo que em Itacoatiara, um dos critérios envolvidos no IDHM - a renda mensal per capita dos domicílios rurais - equivale a 170,00 reais, em média, enquanto entre os domicílios urbanos este valor foi de 303,75 reais em 2010 (BRASIL, 2013). Esta diferença é ainda maior no município de Urucurituba, onde, em média, este valor equivale a 363,32 nas residências urbanas e 167,89 na área rural.

Dentre os dados de escolaridade destes municípios, chamam a atenção as altas taxas de analfabetismo que, percentualmente atingem $24,7 \%$ da população itacoatiarense e $25,1 \%$ dos urucuritubenses, índices superiores àqueles estimados para o estado do Amazonas, 11,5\% (BRASIL, 2013) e para o Brasil, 8,7\% (BRASIL, 2012).

\section{OS PARTICIPANTES DA PESQUISA}

O trabalho de campo foi realizado no período compreendido entre julho e outubro de 2013. Participaram deste estudo 47 estudantes de uma instituição 
de ensino superior do estado do Amazonas, matriculados em duas disciplinas da área de Educação em Ciências: "Instrumentação para o Ensino de Biologia" (7) e "Conteúdos e Metodologias das Ciências" (40). Os estudantes matriculados na primeira disciplina referida pertencem ao curso de Licenciatura em Ciências Biológicas, com sede em Itacoatiara, enquanto aqueles matriculados na segunda pertencem ao curso de Pedagogia (15 em Itacoatiara e 25 em Urucurituba). Ainda em relação aos cursos, vale ressaltar que enquanto o primeiro constitui uma licenciatura regular desta instituição, o segundo está ligado ao Plano Nacional de Formação de Professores da Educação Básica (PARFOR).

Em relação ao gênero, 33 estudantes são mulheres, enquanto os 14 restantes são homens. A faixa etária dos estudantes variou entre 17 e 56 anos. Como se pode observar na Figura 1, a distribuição não foi uniforme entre os cursos, sendo que somente no de Pedagogia de Urucurituba houve equilíbrio entre os gêneros, enquanto nos cursos de Itacoatiara houve predomínio de mulheres, sendo que no curso de Pedagogia deste município não há sequer um homem no curso. Em relação à idade, a distribuição também foi desigual (Fig. 2), sendo que a maioria (85,7\%) dos estudantes do curso regular, em Itacoatiara, possuía menos de 30 anos, enquanto nos cursos do PARFOR, em ambos os municípios, ao contrário, a maioria dos estudantes $(82,5 \%)$ possuía mais de 30 anos.

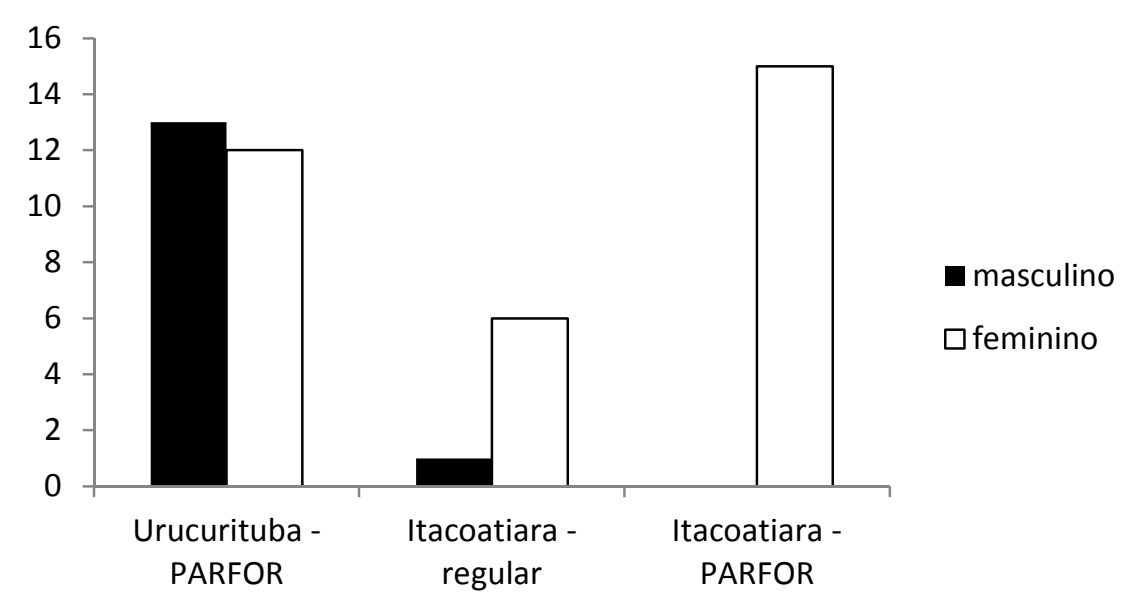

Figura 1 - Distribuição dos gêneros entre os cursos pesquisados. 


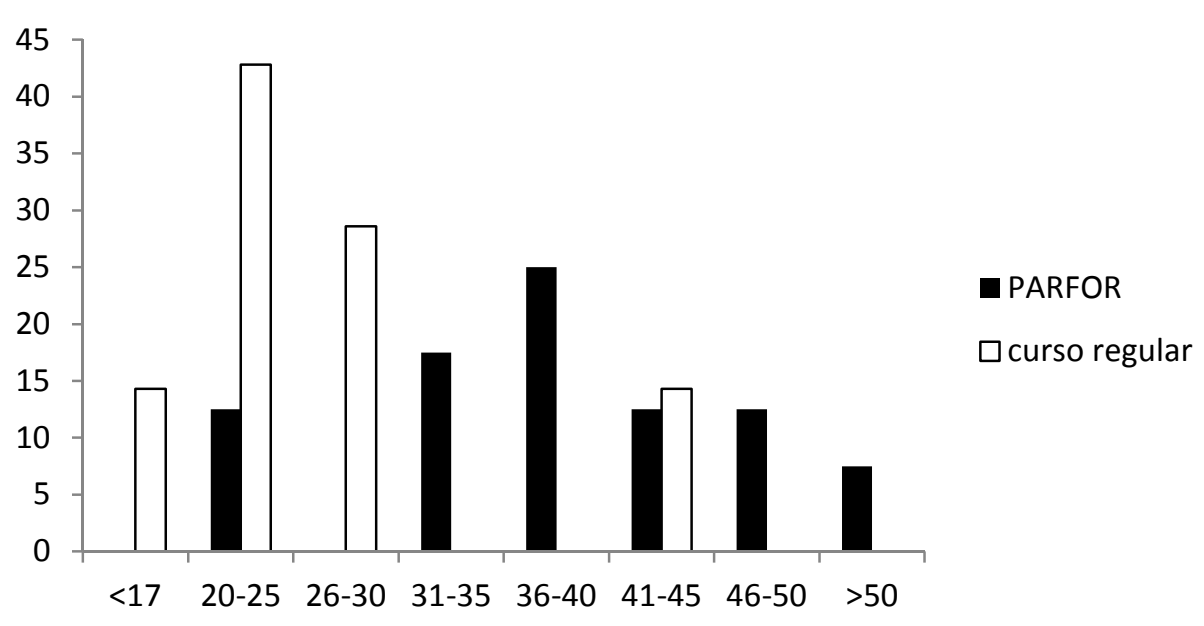

Figura 2 - Distribuição das frequências relativas (\%) das idades dos(as) estudantes participantes da pesquisa por modalidade de curso.

Em relação à distribuição dos estudantes por gênero, com exceção daqueles do curso de Urucurituba, onde houve um equilíbrio entre homens e mulheres, a predominância feminina nas demais turmas observadas, reflete a tradicional distribuição por gêneros observada no magistério da educação básica.

\section{RENDA FAMILIAR, FAMÍLIA, FILHOS}

Perguntados sobre a renda familiar e o número de moradores em suas residências, podemos calcular, a partir das respostas, o rendimento per capita das famílias dos estudantes participantes da pesquisa, cujos resultados, por faixa de rendimentos e por modalidade de curso, podem ser observados na Tabela 1. Quase dois terços dos estudantes $(64,7 \%)$ situou-se na faixa de rendimentos entre $R \$ 100,00$ e $R \$ 400,00$ per capita, enquanto no outro extremo, ou seja, na faixa acima dos $\mathrm{R} \$ 800,00$ mensais podemos observar outra parcela significativa, equivalente a quase um quarto dos participantes da pesquisa (26,4\%). Diferenças nos padrões de renda entre os cursos podem ser observados na primeira faixa de renda dos estudantes do curso de PARFOR de Itacoatiara, evidenciando menor renda entre estes e, no extremo oposto, uma frequência maior de estudantes (mais de $1 / 3$ destes) com rendimentos nas mais altas faixas de renda (acima de $\mathrm{R} \$ 800,00$ ) entre os estudantes do curso 
do PARFOR de Urucurituba. Importante ressaltar que cerca de metade dos estudantes do PARFOR de Itacoatiara não informou a renda ao preencher seus questionários. Ainda assim, a análise dos dados disponíveis, evidencia que, a partir deste critério, não é possível observar diferenças significativas na posição social dos estudantes do curso regular em relação aos do PARFOR.

Tabela 1 - Renda familiar mensal per capita dos estudantes de Itacoatiara e Urucurituba participantes desta pesquisa

\begin{tabular}{lcccc}
\hline \multirow{2}{*}{$\begin{array}{l}\text { Rendimento familiar } \\
\text { per capita }\end{array}$} & \multicolumn{4}{c}{ Frequência relativa (\%) por faixa de rendimentos } \\
\cline { 2 - 5 } & $\begin{array}{c}\text { Urucurituba } \\
\text { PARFOR }\end{array}$ & $\begin{array}{c}\text { Itacoatiara } \\
\text { - regular }\end{array}$ & $\begin{array}{l}\text { Itacoatiara } \\
\text { - PARFOR }\end{array}$ & Total \\
\hline $100-250$ & 30,0 & 33,3 & 62,5 & 38,2 \\
$250-400$ & 25,0 & 33,3 & 25,0 & 26,5 \\
$400-600$ & 10,0 & 16,7 & 0 & 8,8 \\
$600-800$ & 0 & 0 & 0 & 0 \\
$800-1.000$ & 30,0 & 0 & 12,5 & 20,6 \\
$>1.000$ & 5,0 & 16,7 & 0 & 5,9 \\
\hline
\end{tabular}

Comparando o perfil de renda familiar dos estudantes ao restante da população destes municípios, segundo o censo de 2010 (BRASIL, 2013), percebe-se que a parcela da população com rendimentos familiares per capita iguais ou superiores a um salário mínimo é ligeiramente maior entre os participantes da pesquisa (12,5\% no caso dos estudantes do curso regular e $16,7 \%$ entre os do PARFOR) do que entre os itacoatiarenses em geral $(9,0 \%)$. $\mathrm{Na}$ faixa de rendimentos até um s.m. a diferença mais perceptível é que, entre os estudantes, que também são docentes, não há famílias sem rendimentos, como é o caso de $29,8 \%$ dos itacoatiarenses (na área rural esse percentual atinge os $52,4 \%$ ).

A diferença entre a renda familiar dos estudantes de Urucurituba, em relação à população, em geral, é grande. Enquanto entre os primeiros, cerca de $35,0 \%$ possuem rendimentos per capita superiores à $R \$ 800,00$, na população em geral é de $2,6 \%$, sendo que $65,9 \%$ das famílias urucuritubenses recebem até um s.m. e outros $31,6 \%$ informaram, durante o recenseamento (BRASIL, 2013) não possuir qualquer rendimento.

Outro dado socioeconômico observado, a fim de constituir o perfil dos estudantes, relacionou-se à sua prole. Os resultados (Fig. 3) indicam 
diferenças entre os estudantes do curso regular, que, majoritariamente, não possuem filhos $(X=0,14,0-1)$, quando comparados aos do PARFOR, $(X=2,49$, $0-6)$.

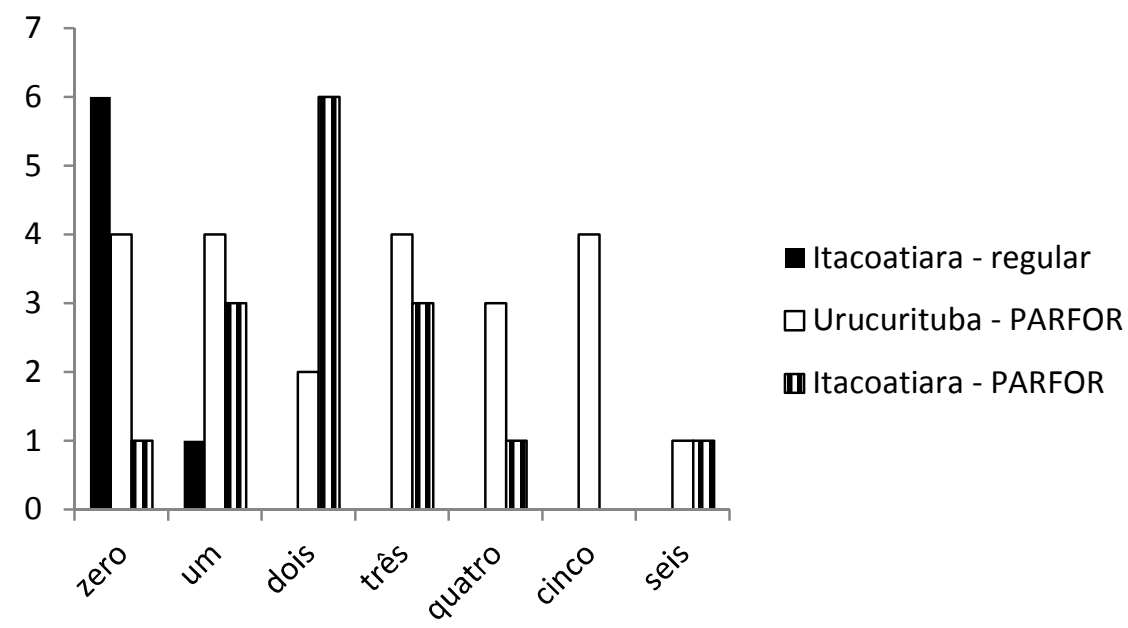

Figura 3 - Tamanho da prole dos estudantes participantes da pesquisa, conforme a modalidade de curso realizado e a localidade.

Associando-se estas três características do perfil socioeconômico dos estudantes (idade, renda familiar e prole) é possível inferir que, ainda que a renda familiar não varie significativamente entre os estudantes das duas modalidades de curso, as diferenças na idade e no número de filhos parecem indicar que enquanto os estudantes do PARFOR são trabalhadores e constituem-se como as principais fontes de renda na família, os do curso regular, com exceções, não possuem rendimentos e tem seus estudos custeados pelos pais ou responsáveis. Corroborando com esta extrapolação, $88,0 \%$ dos estudantes do curso regular afirmaram dedicar-se somente aos estudos.

Nesta condição, ainda que nada indique que os estudantes do curso regular descendem de pais com formação acadêmica, é possível inferir que, não possuindo ocupação remunerada, nem filhos, dispõe de tempo livre para efetivar as leituras e outros exercícios exigidos, ao contrário dos estudantes do PARFOR, que, ao menos nesta instituição, ocupam todo o recesso escolar, inclusive as férias, para estudar em disciplinas ministradas durante oito horas diárias, inclusive aos sábados. 
No caso das estudantes do curso do PARFOR de Itacoatiara, no qual há só mulheres, constitui agravante o fato de que 2/3 destas são trabalhadoras solteiras e com filho(s). No contexto amazônico, no qual mais de 120 mil crianças não possuem registro de paternidade, é frequente 0 descomprometimento do homem no cuidado aos filhos, sobrecarregando as docentes-estudantes (BRASIL, 2009).

\section{CONSTITUIÇÃO/FORMAÇÃO, LEITURAS, ATIVIDADES SOCIAIS E OUTROS ELEMENTOS CULTURAIS}

Quase todos os estudantes $(97,8 \%)$, em sua trajetória escolar, são oriundos de escolas públicas, tendo estudado nestas instituições tanto no ensino fundamental quanto no médio. Utilizam, como meios de transporte, para dirigirem-se à universidade, principalmente motocicletas (46,9\%) e caminhadas $(37,0 \%)$ e, quando provém de áreas rurais, ônibus (8,6\%) e embarcações $(4,3 \%)$.

Ao serem questionados sobre sua participação em movimentos sociais, mais da metade $(57,5 \%)$ dos estudantes afirmou envolver-se com tais atividades, enquanto 19,1\% disseram não participar (outros 23,4\% dos participantes não respondeu a questão). Não houve diferenças, neste quesito, entre estudantes do PARFOR em relação aos do curso regular. Apesar disso, diferenças podem ser observadas entre os estudantes de Itacoatiara, onde a maioria $(63,6 \%)$ não participa de movimentos sociais em relação aos de Urucurituba, no qual os estudantes engajados neste tipo de atividade constituem maioria (76,0\%). Do total dos estudantes que afirmou participar destas, cerca de um quarto (25,5\%) participa atividades ligadas a sindicatos de trabalhadores (rurais e da educação), enquanto outros relataram sua participação em movimentos religiosos (10,6\%), comunitários (8,5\%), e culturais $(2,1 \%)$, além de partidos políticos $(8,5 \%)$.

Além destes aspectos, exploramos, neste estudo, algumas informações sobre atividades de caráter cultural, como leituras, músicas e filmes que constituíram experiências na história de vida dos estudantes. Em relação às leituras, perguntamos a eles quantos e quais foram os livros lidos no último ano e quais são considerados os prediletos. 
Cerca de um terço dos participantes (31,9\%) afirmou não ter lido livro algum no último ano, informação que denota, ao tratarmos de estudantes universitários, frequente deficiência na atividade de leitura neste público. Além disso, outro terço dos estudantes $(31,9 \%)$ não respondeu à questão, além de não ter indicado qualquer título lido, o que parece indicar que este outro grupo de estudantes também, como o primeiro, não realizou a leitura de livros, na íntegra, ao longo do ano. Dentre os que informaram ter realizado leituras, $14,9 \%$ leram somente um livro, enquanto os restantes $12,6 \%$ leram mais de um livro. Dentre as leituras realizadas, as referências mais frequentes foram a livros de caráter religioso e também a livros indicados por docentes das disciplinas que estão cursando, de conteúdos específicos das Ciências da Natureza ou do campo da Educação, com destaque, neste último caso, para os de autoria do educador pernambucano Paulo Freire. Frequentes também foram as menções a livros de autoajuda e a best-sellers. Obras consagradas da literatura, como é o caso de Iracema, de José de Alencar e Carandiru, de Dráuzio Varella, constituíram exceção.

Ao serem questionados sobre seus livros preferidos, percebem-se diferenças qualitativas entre os estudantes do PARFOR que, em sua totalidade $(\mathrm{n}=40)$, mencionaram somente dois títulos, ao passo que os poucos estudantes do curso regular $(n=7)$ participantes desta pesquisa, referiram-se a diversos títulos de obras relevantes em diferentes campos do saber. Pode-se destacar, no campo da literatura, as menções aos romances Dois Irmãos e Relato de um certo oriente do escritor amazonense Milton Hatoum (que, por estes dois títulos, foi laureado com o Prêmio Jabuti de Literatura), as obras $O$ triste fim de Policarpo Quaresma, de Lima Barreto, As pupilas do Senhor Reitor, de Júlio Diniz, Meu pé de laranja lima, de José Mauro de Vasconcelos, entre outras. Foram ainda mencionados importantes autores da literatura universal, como Umberto Eco e Fernando Pessoa. No campo da Biologia, foi referido o clássico livro A origem das espécies, de Charles Darwin. Dentre os títulos mencionados pelos estudantes do PARFOR, cabe destacar A Bíblia Sagrada, que, entre outras obras religiosas denota a presença da religiosidade cristã, elemento cultural presente com grande frequência e intensidade na cultura das pequenas cidades do interior do Amazonas. 
Apesar disso, destaque-se que nem mesmo a forte presença da religião cristã parece capaz de mover os estudantes à leitura. Ao investigar outros elementos, como músicas e filmes preferidos pelos estudantes, as religiões cristãs parecem ter pouca influência sobre as preferências dos estudantes. Mais de $3 / 4$ destes $(78,7 \%)$ não fez qualquer menção a títulos de músicas ou filmes religiosos entre seus preferidos, enquanto menos de $1 / 4$ destes fez referência, dentre outros títulos, a elementos religiosos, particularmente aqueles relacionados a igrejas neopentecostais ou carismáticas. Somente dois estudantes $(4,2 \%$ do total) fizeram referência exclusiva a livros, filmes e músicas de sua religião, denotando a presença majoritária de uma postura culturalmente mais aberta entre os estudantes, que contribui para possibilitar a aprendizagem das Ciências.

Por outro lado, a presença majoritária de elementos da chamada indústria cultural, na música, na literatura e no cinema, "consumidos" por estes estudantes, como best-sellers, filmes hollywoodianos e músicas massificadas denota, como indicado em outra pesquisa envolvendo docentes universitários de Ciências (ODA, 2012), uma visão pouco esclarecida por parte deste público, que se utiliza destes produtos para seu "lazer", desconsiderando o papel formativo destes elementos (OLIVEIRA, 2007).

Entretanto, o quadro sociocultural no qual estão inseridos estes estudantes é distinto, levando-se em conta as características dos dois municípios pesquisados. Enquanto em Itacoatiara existem duas universidades públicas e, ainda que de modo precário e incipiente, a presença de elementos culturais alternativos aos produtos massificados da indústria cultural, no município de Urucurituba não há universidade, há poucos canais de TV (os mais populares) e produtos "culturais" como CDs de músicas massificadas, DVDs de filmes, particularmente dos circuitos hollywoodiano e gospel inundam a cidade, tornando-se onipresentes.

\section{CULTURA, RELAÇÕES SOCIAIS E EDUCAÇÃO EM CIÊNCIAS}

Em estudo recente (ODA, 2013), em que se aborda, tal qual propugnado pelos Parâmetros Curriculares Nacionais do Ensino Médio - PCNEM (BRASIL, 
2002), a transversalidade da educação estética, particularmente no caso da Educação em Ciências, defende-se a importância da apropriação, pelo professor, de elementos da cultura do estudante e sua utilização nas discussões envolvendo Ciência, Tecnologia e Sociedade (CTS). Tal postura é considerada fundante na contextualização dos conteúdos e, mais do que isso, o domínio de elementos do campo da estética pelo professor de ciências é considerado fundamental para evitar o uso de recursos audiovisuais, como obras cinematográficas, de conteúdo científico apropriado, mas limitados do ponto de vista ético-estético.

No referido estudo, o autor sugere que o conjunto da obra do músico e compositor pernambucano Chico Science, cuja temática central é a relação do desenvolvimentismo com a destruição dos mangues de seu estado natal, constitui importante conteúdo para a Educação em Ciências, quer considerando seu conteúdo científico, quer levando-se em conta os elementos estéticos, normalmente relegados à condição de conteúdos do "currículo oculto".

No presente estudo, investigamos elementos socioeconômicos e culturais nos quais estão inseridos estudantes que realizam disciplinas no campo da Educação em Ciências e, presentemente, apresentaremos uma avaliação que envolve os conhecimentos no campo da Educação em Ciências explicitados por eles e outras avaliações acerca de tais conhecimentos no decorrer das disciplinas ministradas.

Inicialmente perguntamos aos estudantes o que seria um bom professor de Ciências. Em suas respostas, houve diferenças significativas entre os estudantes do curso regular em relação aos do PARFOR. Lembrando, nesse caso, que os distintos perfis formativos também podem guardar relação com o fato de que os primeiros são alunos de uma licenciatura, enquanto os segundos cursam Pedagogia.

Foi possível perceber, no caso dos estudantes do PARFOR (Pedagogia), uma valorização de aspectos relacionados: a) ao modo como o docente administra suas atividades, como dedicação, compromisso, dinamismo, responsabilidade, pontualidade, empenho e organização; b) afetivos, como tratar bem os alunos, ter bom relacionamento, ser 
compreensivo, humilde, gostar da profissão e; c) metodológicos, como ouvir os alunos, instigar os alunos a participar, pesquisar, resolver problemas. Entre os estudantes do curso regular (Licenciatura), houve uma predominância de aspectos metodológicos e cognitivos, como menções à problematização, ao saber ouvir, ter preocupações com a aprendizagem, ao invés do ensino, valorizar o conhecimento prévio dos estudantes, não ser conteudista, buscar inovações, buscar motivar o aluno, ter didática, clareza, etc. Características relacionadas ao modo como conduz a profissão, como dinamismo foram pouco referidas, assim como elementos afetivos e éticos, como o gostar do que faz, não criar barreiras hierárquicas, ser respeitoso e disponível.

Tais diferenças apontam para a maior valorização de aspectos pedagógico-cognitivos entre os licenciandos e de aspectos burocráticos, afetivos e pedagógico-cognitivos entre os alunos de Pedagogia. Deste modo, tais características indicam uma avaliação mais ampla por parte dos segundos, que exploraram diversos aspectos do "ser professor". Este olhar mais amplo pode estar relacionado com o fato de que os primeiros ainda não exerceram a profissão, enquanto os segundos são docentes há vários anos.

Dito isso, vale ressaltar que não se afirma aqui que os valores explicitados pelos participantes da pesquisa se reflitam em sua prática docente, mas representam, ao menos, a assimilação, ao longo da experiência, do discurso corrente entre os profissionais do campo da educação.

No tocante à aprendizagem das Ciências, não foram observadas diferenças entre os estudantes em relação à modalidade de curso realizado, com exceção do curso de PARFOR de Itacoatiara. Os estudantes, em geral, apresentam dificuldades com a escrita, evidenciando uma série de deficiências no uso da norma padrão, problemas com a grafia das palavras (acentuação, conjugação verbal, etc.), concordância numérica, com a construção das frases (coerência), etc., como pode ser observado nos excertos abaixo:

A ciência tem várias concepções para o cientista e, em relação ao papel social, na minha concepção, os cientistas sem a ciência. não teria cientista e, através da ciência... (Ludmila, nome fictício, Pedagogia, Urucurituba).

...faz-se necessario que o cidadão tenha uma compreenção básica de como usar e controlar em prol de uma melhor 
qualidade de vida. (Laura, nome fictício, Pedagogia, Itacoatiara).

...entender de maneira cientifica o meio onde vivo. como tudo funciona, e toda sua impotancia (Maria, nome fictício, Licenciatura em Biologia, Itacoatiara).

Cabe destacar aqui, antes de passar para as questões de conteúdo relativas às concepções de ciência dos estudantes, que uma das características marcantes observadas no curso do PARFOR de Itacoatiara que o distinguiram dos demais estudantes é relativa a falta de disposição que demonstraram para a execução de tarefas relacionadas à produção escrita. Com grande frequência pode-se observar a presença de textos integralmente copiados de artigos e livros em exercícios solicitados aos estudantes. Até mesmo exercícios envolvendo textos de ficção, como contos, fábulas e crônicas foram, frequentemente, copiados. Deste modo, foi, em grande medida, prejudicada uma efetiva avaliação da produção escrita destes estudantes, cuja escrita "real" ficou subsumida entre parágrafos de textos plagiados.

Num questionário sobre concepções de ciência, por exemplo, - atividade realizada em grupo - numa das questões em que se perguntava sobre sua finalidade, foi comum a ocorrências de respostas muito parecidas entre estas estudantes e que versavam sobre assunto diverso do enunciado da questão. Algumas respostas a esta questão, por exemplo, falaram da importância do Ensino de Ciências, como é o caso da resposta abaixo:

O ensino de Ciencias serve para estimular ainda mais a curiosidade natural das crianças pela natureza. (Neide, nome fictício, PARFOR, Itacoatiara).

Perfil distinto foi observado nas demais turmas, nas quais os textos, ainda que contenham inúmeros problemas sintáticos e semânticos, conforme mostrado anteriormente, eram claramente da autoria dos estudantes, que se esforçavam para realizar os exercícios, a despeito das dificuldades que encontravam, executando as correções solicitadas, quantas vezes fosse necessário.

Em relação a questões envolvendo a natureza da Ciência, de igual modo, não foram observadas diferenças entre os cursos nas distintas 
modalidades. Deste modo, o maior volume de leitura apresentado pelos estudantes do curso regular não contribuiu significativamente nem para que pudessem utilizar, de modo mais competente, a norma padrão, nem para que melhorassem sua compreensão sobre a epistemologia da Ciência.

Muitos dos problemas apontados por Gil-Perez et al. (2001) em relação a visões de ciência entre docentes, foram observadas entre os participantes do presente estudo. Os autores acima mencionados referem, por exemplo, "imagens deformadas" de ciência entre professores, caracterizadas por conceberem-na como aproblemática e ahistórica, exclusivamente analítica (p. 131), como acumulativa e de crescimento linear (p. 132), como individualista e elitista (p. 133), além de descontextualizada e socialmente neutra (p. 133).

Algumas das posições observadas no presente estudo afirmam a ciência como socialmente neutra e capaz de, com suas práticas, "descobrir as coisas":
Através da ciência que eles (os cientistas) estudam e descobrem as coisas, através dela podemos saber e fazer varias descobertas (Paulina, nome fictício, PARFOR, Urucurituba).
A importância é a de descoberta que eles trazem através dos seus conhecimentos, e avanços da tecnologia e a globalização (Maura, nome fictício, PARFOR, Itacoatiara).
A ciência serve para identificar o mundo (Elizabeth, nome fictício, PARFOR, Itacoatiara).

A fala de Maura, além disso, mistura, indevidamente, a ciência e a tecnologia, além de carregar também uma visão de acumulação e crescimento linear, como esta, apresentada a seguir:

A ciência faz a humanidade evoluir. É graças a ela que nossa vida está mudando (Laila, nome fictício, PARFOR, Urucurituba).

A ciência serve hoje, principalmente para o avanço das tecnologias e científico (Paula, nome fictício, PARFOR, Urucurituba).

Uma visão similar à de neutralidade social é a de ciência enquanto um empreendimento para o "bem da humanidade", igualmente ingênua e "deformada":

Para mim o cientista se preocupa com os seres humanos, tanto que através de suas experiências e interesses ele consegue 
solução na vida humana (Paulo, nome fictício, PARFOR, Urucurituba).

Outra visão comumente explicitada pelos participantes desta pesquisa e ausente no estudo de Gil-Peres et al. (2001) reflete uma percepção empirista das Ciências, ou seja, carrega a ideia de que a ciência é produzida por meio da experiência, dos experimentos e, portanto, não analítica, como no caso das seguintes falas:

Sobre a ciência precisamos ir a campo, pesquisando observando tudo o que há no ambiente (Adna, nome fictício, PARFOR, Urucurituba)

Ciência referece a tudo que aprendemos e que é comprovado cientificamente por meio de experiências (Lia, nome fictício, PARFOR, Itacoatiara).

Ressalte-se que, destas falas, não houve, dentre elas, alguma que expressasse uma visão mais contemporânea de ciência, parametrizada pela ideia de empreendimento coletivo, falível, historicamente situada e não neutra. Ainda assim, as atividades envolvendo concepções de ciência, realizadas com os estudantes, possibilitaram que estes pudessem aperfeiçoar sua escrita e melhorar também suas compreensões acerca da natureza da ciência.

\section{CONSIDERANDOS E (IN)CONCLUSÕES}

As transformações pelas quais passa o ensino superior, tanto no Brasil quanto em outros países, estão relacionadas, sobretudo, com a maior democratização do acesso às universidades. Tais mudanças tem trazido, para o seio destas, uma parcela da população caracterizada por entrada tardia na universidade, menor poder aquisitivo, pioneirismo na vida intelectual dentro da família e entrada precoce no mundo do trabalho. Estes novos estudantes ingressam, portanto, desprovidos de algumas características formativas mais frequentes entre o público tradicionalmente acadêmico, de classe média, sobretudo o hábito da leitura, o contato com obras clássicas da literatura e do cinema, entre outros. 
Os estudantes participantes desta pesquisa, moradores de dois municípios do interior do Amazonas, parecem integrar este perfil do "novo estudante universitário", sobretudo os do PARFOR, que são estudantestrabalhadores, com filhos e ingressando tardiamente no ensino superior.

Tal quadro, de fraca preparação para a atividade acadêmica é agravado por um contexto social em que diversos elementos formativos importantes para os estudantes, como livros, obras cinematográficas e atividades culturais encontram-se quase ausentes do cotidiano destes estudantes, sendo substituídos por elementos ligados à prática religiosa ou à indústria cultural. A situação é ainda mais aguda no município de Urucurituba, no qual não existe sequer uma faculdade ou universidade.

Apesar disso, evidenciou-se maior participação, interesse e engajamento dos estudantes às atividades de ensino entre os estudantes do PARFOR de Urucurituba do que entre as estudantes da mesma modalidade em Itacoatiara. Considerando o caráter coletivo das atividades acadêmicas, o maior envolvimento dos alunos de Urucurituba com atividades sociopolíticas, pode ter contribuído para facilitar o debate e a produção de sínteses das discussões e, portanto, a execução destas tarefas.

Registre-se, entretanto, a situação desfavorável das estudantes, trabalhadoras, mães e solteiras que, conforme apontam os dados do censo escolar (BRASIL, 2009), com frequência não contam com o apoio material e afetivo dos pais de seus filhos, acumulando, portanto, as tarefas domésticas, profissionais e acadêmicas.

Registre-se, mais do que isso, a precariedade de condições dos estudantes do PARFOR, em relação aos estudantes de cursos regulares. À guisa de contribuir para a formação dos docentes da rede pública, o estado oferece um ensino com sobrecarga de horas-aula diárias, sem intervalos adequados para estudos e sem oferecer aos docentes o afastamento do trabalho, oferecendo aos professores um curso que se realiza no recesso escolar e em seu período de férias. Tal situação, além de comprometer o rendimento dos docentes-estudantes no curso de graduação, possivelmente compromete o planejamento escolar, afastando os professores em curso de suas escolas durante a realização desta atividade. 
Além destes fatores, é importante, lembrar, finalmente, que, os municípios do interior do estado do Amazonas, conforme já apontado anteriormente, caracterizam-se por baixos IDHs, altas taxas de analfabetismo, alta frequência de famílias de baixa renda (e mesmo sem renda) e, no caso do público-alvo desta pesquisa, um reduzido número de indivíduos com nível superior. A cultura acadêmica, nestas localidades, o afluxo de professores universitários pós-graduados, os intercâmbios culturais com outras instituições de ensino, são fatos recentes e tendem a produzir mudanças a longo prazo nestes municípios.

Cabe aos docentes universitários, neste contexto, compreender a realidade social na qual estão inseridos estes estudantes, além de desenvolver atividades adequadas a este contexto, particularmente àquelas relacionadas com a produção textual e com a leitura, possibilitando que adquiram tais hábitos, tais comportamentos, utilizando-se, quer de textos literários, quer da literatura científica, mas, sobretudo, buscando inserir, no cotidiano dos estudantes, o gosto pela leitura. Somente deste modo, formando leitores autônomos, será possível superar as deficiências formativas, quer no campo da leitura e da escrita, quer no campo dos conteúdos científicos, melhorando, deste modo, as habilidades argumentativas dos estudantes e o domínio e apropriação dos conceitos científicos.

\section{REFERÊNCIAS BIBLIOGRÁFICAS}

BRASIL. Resolução CNE/CP № 1, de 18 de Fevereiro de 2002. Institui Diretrizes Curriculares Nacionais para a Formação de Professores da Educação Básica, em nível superior, curso de licenciatura, de graduação plena. Disponível em <http://portal.mec.gov.br/seesp/arquivos/pdf/ res1 a.pdf>. 2002a. Acesso em 6 de junho de 2014.

BRASIL. Censo Escolar - Sistema Educacenso. Instituto Nacional de Estudos e Pesquisas Educacionais (INEP). Ministério da Educação. 2009. Disponível em <http://www.mec.gov.br/inep>. Acessado em 10 de julho de 2014. 
BRASIL. Pesquisa Nacional por amostra de domicílio (Pnad). Instituto Brasileiro de Geografia e Estatística (IBGE). 2012. Disponível em http://ibge.gov.br/pnad

BRASIL. Dados do Censo 2010. Publicados no Diário Oficial da União no dia 04/11/2010. Disponível em: $<$ http://cidades.ibge.gov.br/xtras/perfil.php?codmun $=130440>$. Acessado em 12 de junho de 2014. 2013.

BRITTO, L. P. L., SILVA, E. O., CASTILHO, K. C., ABREU, T. M. Conhecimento e Formação nas IES Periféricas: perfil do aluno "novo" da Educação Superior. Avaliação, Campinas, v. 13, n. 3, p. 777-791, nov. 2008.

GIL-PEREZ, D.; MONTORO, I. F.; ALÍS, J. C.; CACHAPUZ, A.; PRAIA, J. Para uma imagem não deformada do trabalho científico. Ciência \& Educação, Bauru, v. 7, n. 2, p. 125-153, 2001.

MAURITTI, R. Padrões de vida dos estudantes universitários nos processos de transição para a vida adulta. Sociologia: problemas e práticas, n.ำ 39, 2002, pp. 85-116.

MORAES, C. A. S., BOTELHO, T. M., FONSECA, T. A., ALMEIDA, D. O., BASTOS, J. C. O estudante do ensino superior: identificando categorias de análise. Vértices, Campos dos Goytacazes/RJ, v. 13, n. 3, p. 205-218, set./dez. 2011.

ODA, W. Y. A docência universitária em biologia e suas relações com a realidade das metrópoles amazônicas. 2012. 358 f. Tese (Doutorado em Educação Científica e Tecnológica) - Universidade Federal de Santa Catarina, Florianópolis, 2012.

O que há de Science no Chico Science? Cadernos CIMEAC, Ribeirão Preto, v. 3, n. 1, 2013.

OLIVEIRA, B. J. História da Ciência no Cinema 2. Brasília: CAPES; Belo Horizonte: Argvmentvm 2007.

ONU. Programa das Nações Unidas para o Desenvolvimento (PNUD). Atlas Brasil 2013. Organização das Nações Unidas. 2013. Disponível em: $<$ http://www.pnud.org.br>. Acessado em 5 de junho de 2014. 2013.

PORTES, E. A. Algumas dimensões culturais da trajetória de estudantes pobres no ensino superior público: o caso da UFMG. Revista Brasileira de Estudos Pedagógicos, Brasília, v. 87, n. 216, p. 220-235, maio/ago. 2006.

Urucurituba. Prefeitura Municipal de Urucurituba, Amazonas. Página oficial. Disponível em: <http://www.aam.org.br/prefeituras/376-prefeitura-municipal-deurucu-rituba>. Acessado em 7 de julho de 2014. 
ZAGO, N. Do acesso à permanência no ensino superior: percursos de estudantes universitários de camadas populares. Revista Brasileira de Educação, São Paulo, v. 11, n. 32, p. 226-237, maio/ago. 2006. 